Revista Herencia Vol. 28 (1), 85-92, 2015

Recibido 18-03-2015 Aprobado 24-04-2015

\title{
Un viaje por curiol. Cambiando LA PERSPECTIVA SOBRE LA eXtracción del pigmento en LA ALfarería guANACASTECA
}

\begin{abstract}
RESUMEN
Como parte de los resultados del Proyecto para la Denominación de Origen de la cerámica de San Vicente y Guaitil, localidades de la provincia de Guanacaste, se logró apreciar el proceso de extracción de los pigmentos con los que la alfarería de la zona es decorada. En este artículo se detalla dicha práctica y a su vez se profundiza en el tabú de extracción de este material, presente dentro del imaginario de ceramistas de la zona.
\end{abstract}

Palabras claves: Denominación de Origen, San Vicente, Guaitil, cerámica, curiol.

\begin{abstract}
As part of the results of the project intended to give the Certificate of Origin to the pottery of San Vicente an Guaitil (Guanacaste province), it was achieved to witness the extraction process for the pigment with the pottery is often decorated. This practice is detail in the article, as it goes deeply into the taboo that the actual potters of the area had regarding the extraction of this material.
\end{abstract}

Keywords: Certificate of Origin, San Vicente, Guaitil, pottery, curiol.

Fernando Camacho Mora. Arqueólogo graduado de la Universidad de Costa Rica. Ha desarrollado proyectos de investigación en el campo de la alfarería tradicional.

Su área de interés es la cerámica precolombina, en tanto facilita el estudio de los procesos sociales que han permitido generar cambios en los modos de vida de las poblaciones precolombinas y su relación con la sociedad actual. fercamachomora@gmail.com
En los meses de marzo a diciembre de 2014, la Cátedra de Cerámica de la Universidad de Costa Rica llevó a cabo un proyecto que buscaba dotar a los grupos de artesanos ceramistas de Guaitil de Santa Cruz y San Vicente de Nicoya (provincia de Guanacaste) de las herramientas necesarias para asegurar que sus piezas pudieran tener una Denominación de Origen (figura legal con la que se pueden amparar para evitar que otras personas falsifiquen sus piezas).

A partir de un repaso por la historia arqueológica de la zona, el trabajo arqueológico ejecutado en dicho proyecto correspondió a la sensibilización de ceramistas de su herencia precolombina. Para esto, se profundizó en el papel que la cerámica desempeñó como producto, y a la vez productor, de la sociedad que la utilizó.

Entre de los resultados obtenidos en este proyecto, se logró presenciar la práctica de extracción de los pigmentos con los que las vasijas son decoradas; la cual es conocida únicamente por conversaciones (que datan desde 1950) con alfareros, pero que, hasta este momento, no había sido documentada. En este 

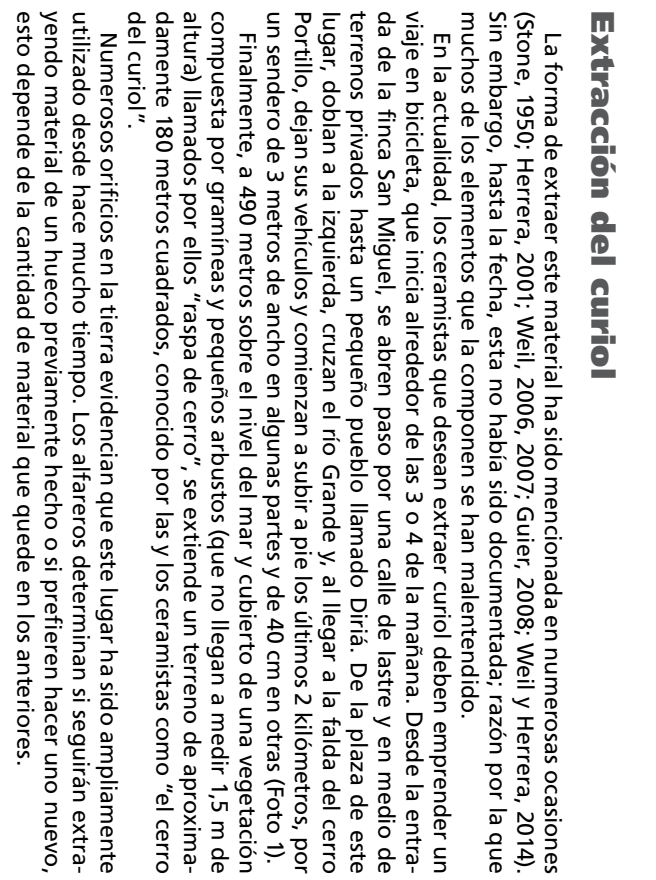

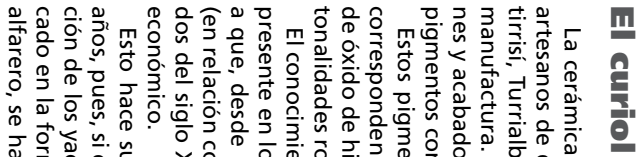

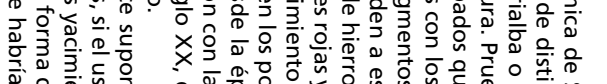

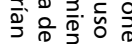

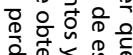

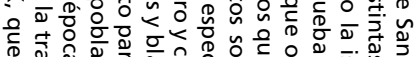

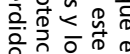

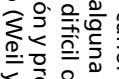

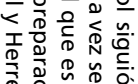

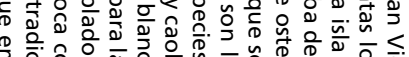

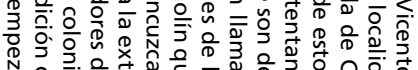

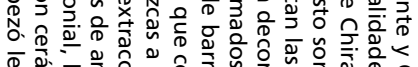

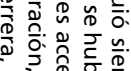

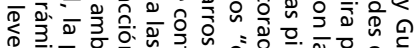

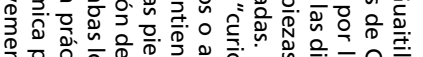

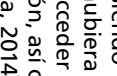

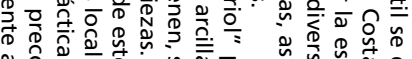

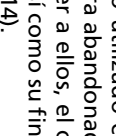

을

突。

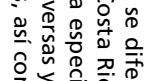

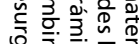

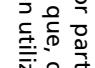

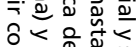

声船 응

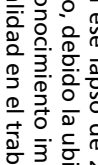

उ ㅇํㅇ

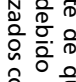

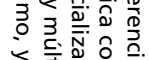

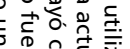

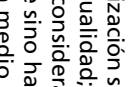

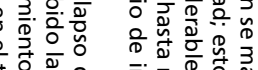

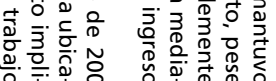

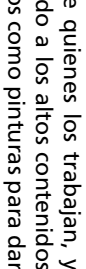

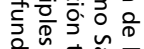

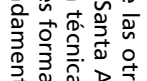

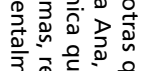

弯

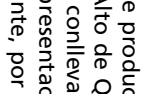

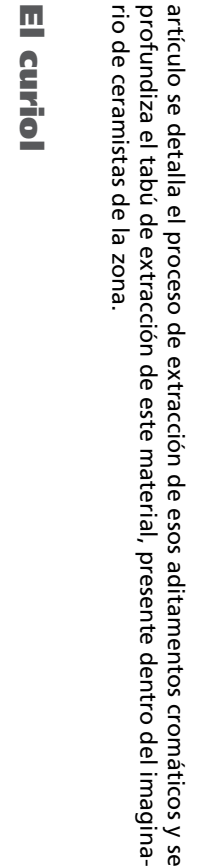

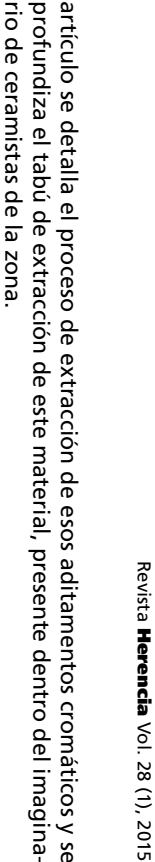
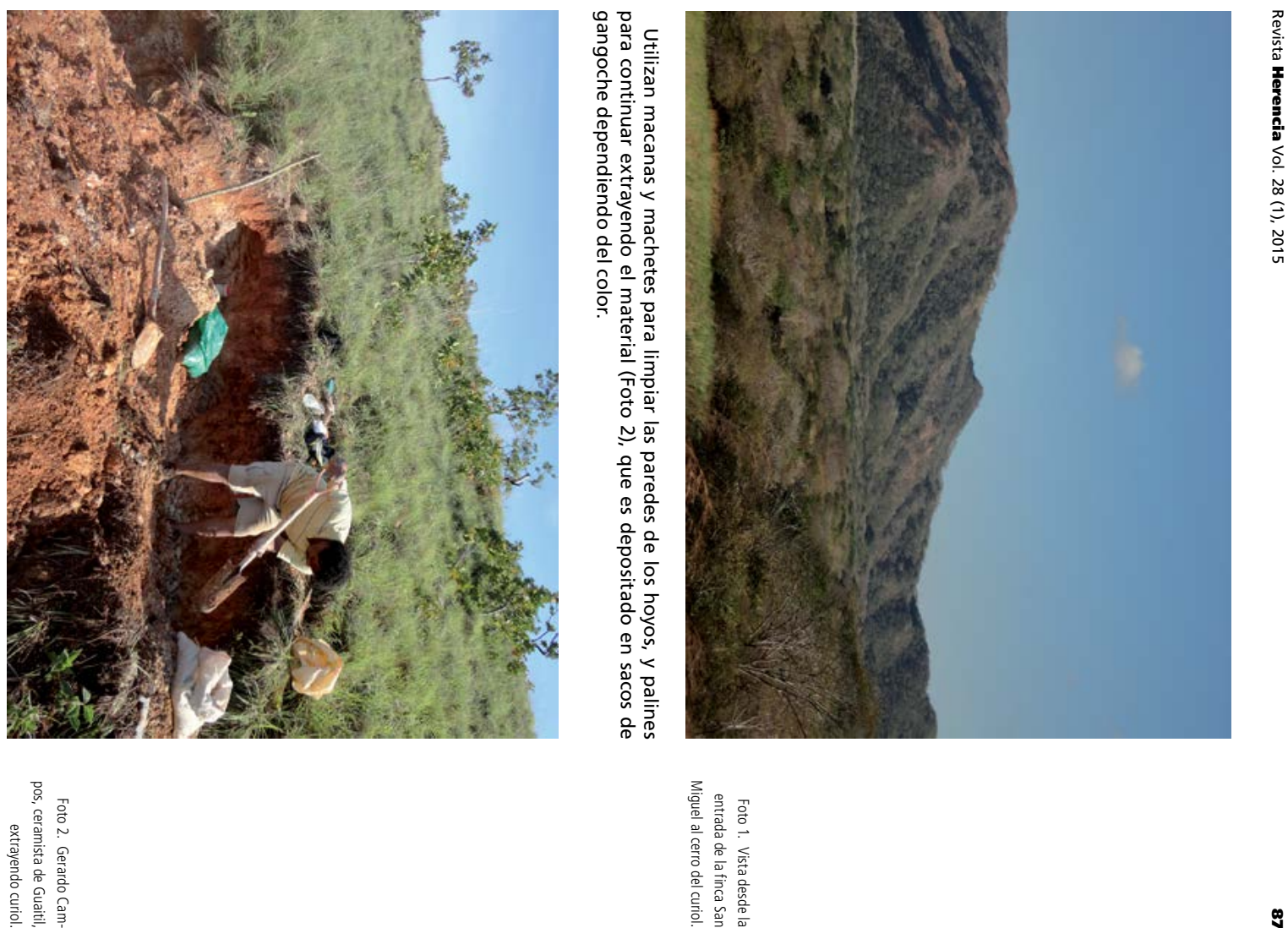

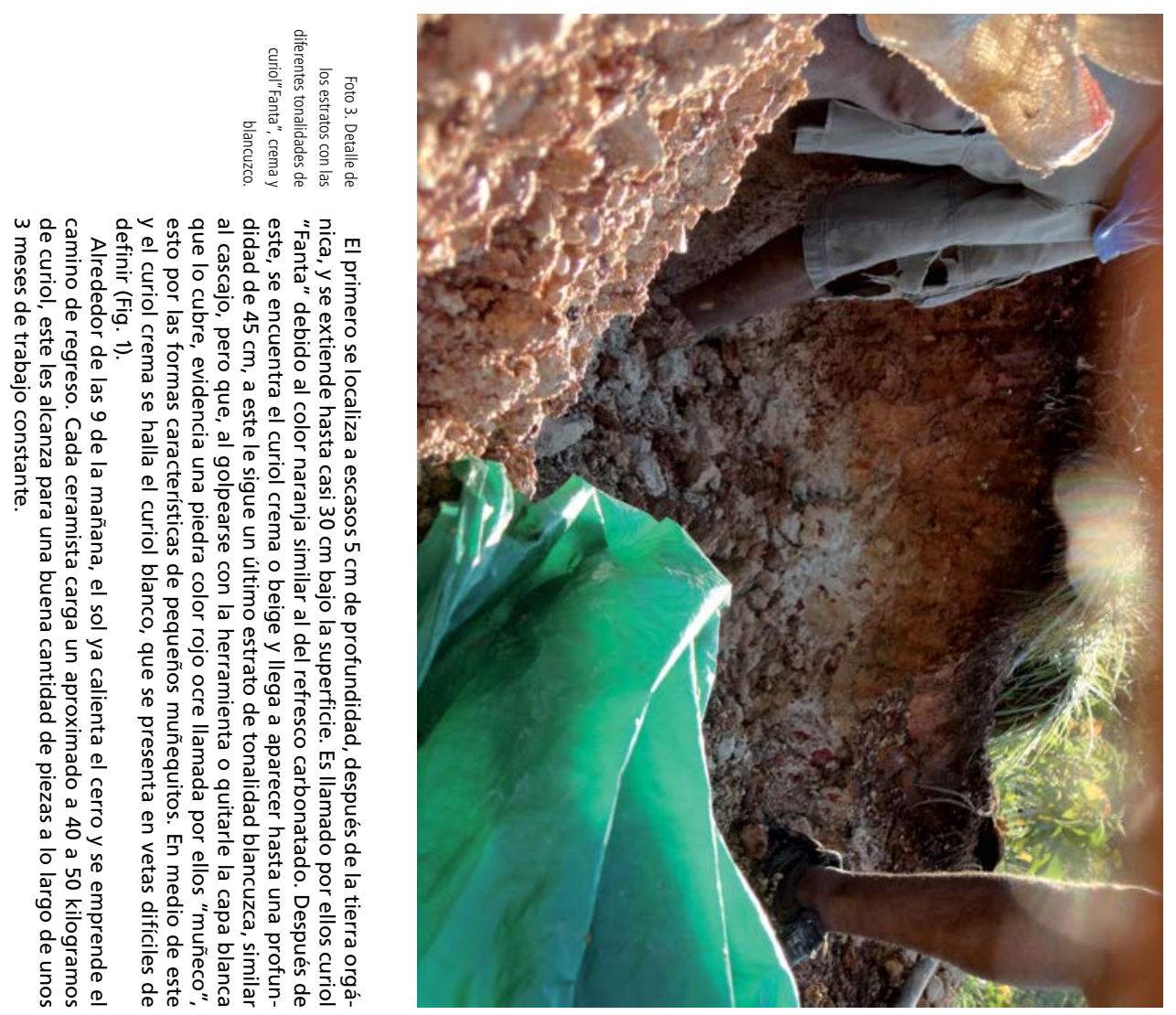

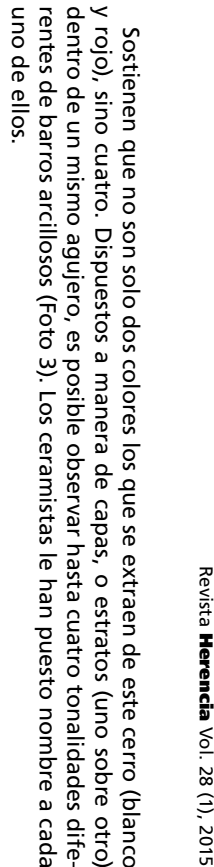
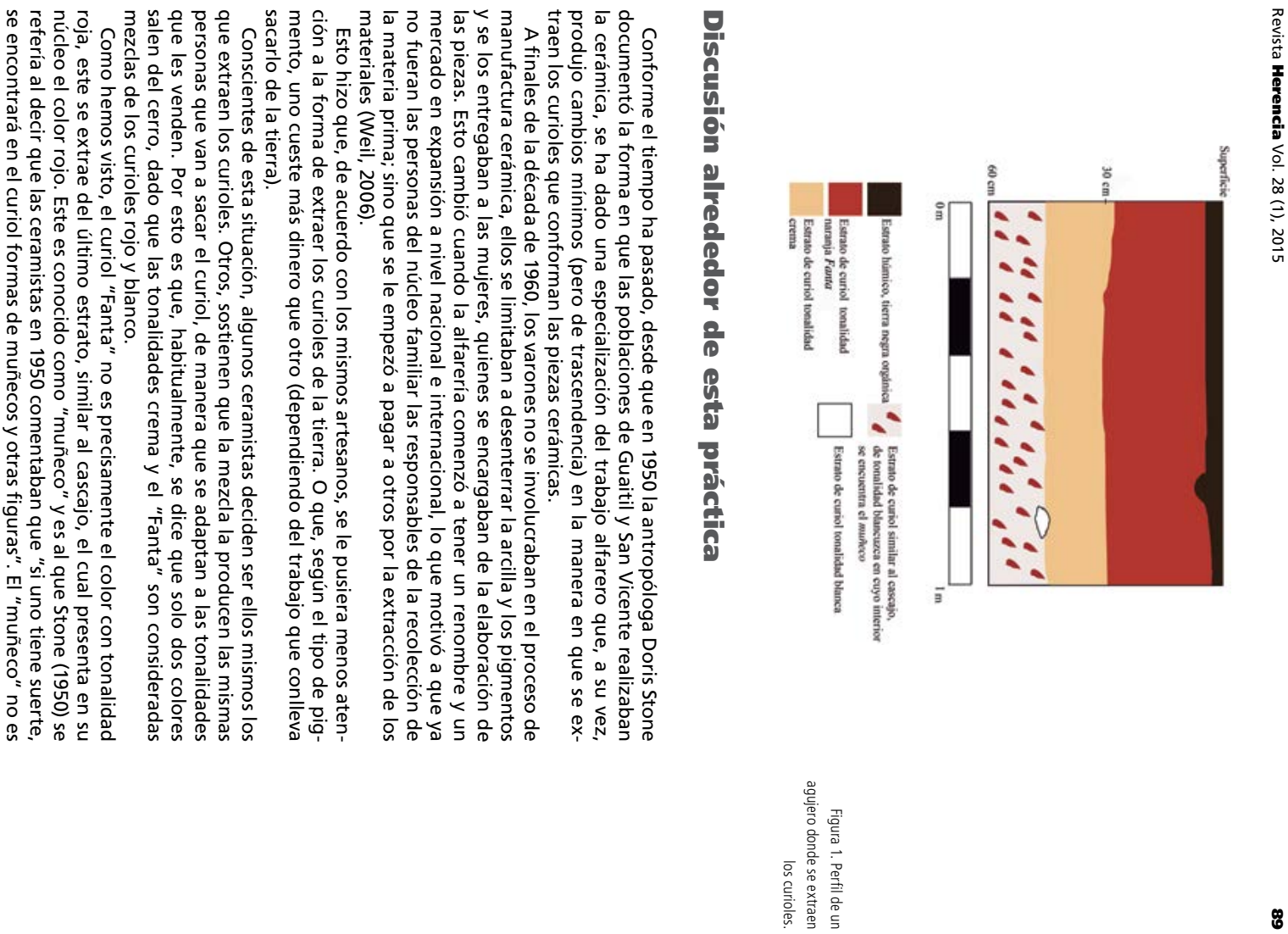


